\title{
Association of number of children and birth order with body mass index in children and adolescents: The CASPIAN-V study
}

\section{Zeinab Hemati}

Isfahan University of Medical Sciences

Nafiseh Mozafarian

Isfahan University of Medical Sciences

\section{Ramin Heshmat}

Tehran University of Medical Sciences

\section{Hadith Rastad}

Alborz University of Medical Sciences

Hanieh-Sadat Ejtahed

Tehran University of Medical Sciences

\section{Seyede Shahrbanoo Daniali}

Isfahan University of Medical Sciences

Masoomeh Goudarzi

Isfahan University of Medical Sciences

\section{Mohammad Esmaeil Motlagh}

Ahvaz Jundishapur University of Medical Sciences: Ahvaz Jondishapour University of Medical Sciences

\section{Mostafa Qorbani (D mqorbani1379@yahoo.com)}

Alborz University of Medical Sciences https://orcid.org/0000-0001-9465-7588

\section{Roya Kelishadi}

Isfahan University of Medical Sciences

\section{Research}

Keywords: Body mass index, Birth-order, children, adolescents

Posted Date: March 10th, 2021

DOl: https://doi.org/10.21203/rs.3.rs-233592/v1

License: (9) (1) This work is licensed under a Creative Commons Attribution 4.0 International License. Read Full License 


\section{Abstract \\ Background}

This study aimed to evaluate the association of the number of family children and birth order with later body mass index (BMI) in a pediatric population.

\section{Methods}

This cross-sectional nationwide study was conducted in the framework of the fifth survey of a national school-based surveillance program, entitled Childhood and Adolescence Surveillance and Preventlon of Adult Noncommunicable disease (CASPIAN-V) Study. Participants were 14,400 students, aged 7-18 years, who were selected by random cluster sampling from 30 provinces in Iran. Multinomial regression models were used to evaluate the odds ratio (OR) and $95 \%$ confidence intervals (95\% $\mathrm{Cl}$ ) of the number of family children or the birth order for later excess weight.

\section{Results}

The first-born children had significantly higher OR for obesity, and the third-born children had higher OR of underweight compared to the first-born ones (OR 1.22, 95\% Cl 1.05-1.42). Moreover, children within the three-, four-, and five-child families had higher OR of underweight than those with one-child families (OR $0.88,95 \% \mathrm{Cl} 0.77-1)$.

\section{Conclusion}

The birth order and number of children were associated with underweight and overweight or obesity in children and adolescents. Future studies are necessary to assess the underlying determinants.

\section{Background}

The epidemic of non-communicable diseases (NCD) is a global problem that is expected to rise considerably in low- and middleincome countries (1). Excess weight is one of the most common risk factors for most NCDs. Growing body of evidence exists about the worldwide increase in the mean body mass index (BMI) (2), as well as the prevalence of obesity and overweight (3), with substantial variation in levels and trends in different countries $(1,4)$. The origin of obesity in children is complex, and multiple factors including genetic, social, cultural, and behavioral factors seems to interact $(5,6)$.

Research has suggested that the changes in family structure can affect the risk of obesity in children $(5,7)$. Some studies have found that only children with higher BMI and greater fat mass are at a greater risk of fatness or obesity (8-10). Although some authors explored the impact of birth order on the occurrence of obesity, they have not come up with consistent findings. For instance, some authors showed that higher BMI is correlated with greater fat mass in firstborn children (11-13). However, such associations were not confirmed by other studies $(9,14)$. It has also been shown that children are at a lower risk of obesity in families with a larger number of children $(5,7)$.

The influence of birth order and/or number of siblings on adolescent body composition can be explained from both biological and social perspectives. For instance, it has been observed that lower-birth-order infants are more likely to be smaller at birth than laterborn children $(15,16)$ and they tend often to experience catch-up growth, which is a growth pattern associated with obesity risk (14). On the other hand, as lower-birth-order children have fewer siblings they have fewer opportunities for playing games and doing other physical activities (17).

Given birth order and total number of siblings are mathematically correlated; it is not possible to measures their respective conditional effects on overweight/obesity, as each factor is adjusted for the other. A study attempted to measures these effects separately by dividing the number of siblings into younger and older categories and then comparing the models covering both

Page 2/11 
younger and older siblings with a model that included just the total number of siblings. It was shown that compared to birth order, the total number of children was a stronger predictor of overweight/obesity (16). Given the reduction of fertility rates worldwide (17) and the increasing number of families with only 1 child (18) a systematic analysis of the influence of these demographic changes on overweight and obesity is essential. Thus, the present study aimed to determine the association between the number of children, birth order, and later BMI in a large nationally-representative sample of children and adolescents.

\section{Methods}

This nationwide cross-sectional study was conducted as part of the fifth survey of a surveillance program entitled "Childhood and Adolescence Surveillance and Prevention of Adult Non communicable disease study" (CASPIAN study). This study was accomplished among 7-to 18-year-old students in primary and secondary schools of urban and rural areas of 30 provinces of Iran using multistage, stratified cluster sampling method (19). Stratification was performed in each province based on the living area (urban/rural) and level of education (primary/ secondary). The sampling size was proportional to population in each province with equal sex ratio. This means that the number of boys and girls was the same in each province. There were 48 clusters in each province and 10 statistical units in each cluster, thus a total of 14,400 students participated in this study at national level. A comprehensive description of the protocol is previously described (19).

\section{Procedure and measurements}

The data collection process was performed by trained health care professional team, and after identifying students based on inclusion criteria, the mission and purpose of the study was explained to them. Then informed consent form and questionnaires were completed through interview with students and their parents. Specific questionnaires were extracted from the World Health Organization-Global School Student Health Survey (WHO-GSHS) (20). Validity and reliability of the Persian translated version of this questionnaire was confirmed in a previous study (21).

Physical examination was performed under standard anthropometric techniques by a team of trained health care experts. Weight was measured to the nearest $0.1 \mathrm{~kg}$ using a calibrated scale placed on a flat ground, and height was measured to the nearest 0.1 $\mathrm{cm}$ using a portable stadiometer (22). BMI was calculated as weight $(\mathrm{kg})$ divided by height squared $\left(\mathrm{m}^{2}\right)$. Waist circumference was measured to the nearest $0.1 \mathrm{~cm}$ three times, and the average of three values was used for the analyses. A non-elastic tape was used to measure waist circumference at a point midway between the lower border of the rib cage and the iliac crest at the end of normal expiration (23).

\section{Definition of terms}

To evaluate the screen time (ST) behaviors, the number of hours per day individuals spent watching television (TV) and/or videos, personal computer, or electronic games was calculated. ST was categorized into two groups: less than $2 \mathrm{~h}$ per day was defined as low, and $2 \mathrm{~h}$ per day or more was defined as high group (24).

Socioeconomic status (SES) included father's job and education, mother's job and education, having private car and computer, and type of student's school (private, public) variables, summarized under one main component, by principle component analysis (PCA) method. SES was categorized into tertiles. The first tertile was defined as a low SES, the second tertile as a moderate, and the third tertile as a high. To define healthy and unhealthy eating behaviors, students were asked to determine the frequency of consumption of breakfast, fruit, vegetables, milk, sugar sweetened beverages (carbonated drinks and synthetic fruit juices), fast foods (sausages, hamburgers and pizza), sweets (cakes, candies, biscuits, and chocolates), and salty snacks (chips, pretzels, and salty puff pates). According to PCA method, two factors were loaded in PCA method; in the first factor, consumption of breakfast, fruit, vegetables, and milk was loaded, which was defined as healthy eating behavior, and in the second factor, intake of sugar sweetened beverages, fast foods, sweets, and salty snacks were loaded, defined as unhealthy eating behavior. Healthy and unhealthy eating behavior factor was categorized into tertiles. The first tertile was defined as low, the second tertile as moderate, and the third tertile as high.

Physical activity (PA) was assessed through a validated questionnaire (25) included weekly frequency of leisure time physical activity outside the school. Having sufficient physical activity was defined as at least 30 min of exercise per day that led to

Page 3/11 
sweating and large increases in breathing or heart rate. Physical activity was categorized into two groups: the first group was defined as low and the second group as high.

WHO growth curves were used to categorize BMI; to define underweight as age and sex-specific $\mathrm{BMI}<5$ th percentile, overweight as age and sex-specific BMI between 85th -95th percentile, and obesity as BMI for >95th percentile for age and sex (26). Parents were also asked about their BMI and history of suffering from obesity and diabetes during their lives.

\section{Ethical concerns}

Study protocols were reviewed and approved by ethical committees and other relevant national regulatory organizations. The Research and Ethics Council of Isfahan University of Medical Sciences approved the study (Project Number: 194049). After complete explanation of the study objectives and protocols, written informed consent and verbal consent were obtained from the parents and students, respectively.

\section{Statistical analysis}

STATA package ver. 11.0 (Stata Statistical Software: Release 11. College Station, TX: Stata Corp LP. Package) was used. All statistical measures were estimated using survey data analysis methods. Results were provided as mean and standard deviation (SD) for continuous variables and as percentage for categorical variables. Multinomial regression models were used to evaluate the odds ratio (OR) and $95 \%$ confidence intervals $(95 \% \mathrm{Cl})$ of "the number of children" or "birth order" for underweight, overweight and obesity. Adjustment has been done for sex, age, region, birth weight, physical activity, screen time, socio-economic status, parental BMI, obesity history, and diabetes history.

\section{Results}

From 14274 enrolled students with mean age of $12.3 \pm 3.2 \mathrm{y}, 7228(50.6 \%)$ were boys. Mean of BMI was $18.5 \pm 4.7 \mathrm{~kg} / \mathrm{m}^{2}$, and the prevalence of underweight, overweight, and obesity was estimated $16.1 \%, 9.4 \%$, and $11.4 \%$, respectively. The average age of mothers and fathers at the time of birth was 25.87 and $31.1 \mathrm{y}$, respectively.

The characteristics of students according to the BMI status are presented in Table 1. There was no significant difference in parental age at the time of the child's birth among children's BMI status groups. There were significant differences in terms of birth order and the number of children according to the children weight status $(P<0.001)$ as prevalence of obesity was higher in the first children of families as well as singletons and those with one sibling. Moreover, there were significant differences in sex, residence area, physical activity, and SES among the children BMI status groups $(P<0.05)$. Parental BMI was significantly different among the children BMI status groups $(P<<0.001)$; as obese children had parents with larger BMI compared to other groups $(P<0.05)$. Age of children was also significantly different among children BMI status groups $(P<<0.001)$. Post hoc analysis showed that the underweight children were significantly younger compared to the normal weight and overweight groups $(P<0.05)$. Moreover, there was significantly difference in children age between overweight and obese groups $(P<0.05)$. 
Table 1

Characteristics of the study population according to the child weight status: CASPIANV study

\begin{tabular}{|c|c|c|c|c|c|c|}
\hline & & Underweight & Normal weight & Overweight & Obese & Pvalue \\
\hline Age, mean (sd) & & $12.02(3.05)$ & $12.3(3.2)$ & $12.54(3.05)$ & $12.2(3.06)$ & $<0.001^{*}$ \\
\hline \multirow[t]{2}{*}{ Sex } & Boy & $1248(54.8)$ & $4400(49.4)$ & $621(46.7)$ & $896(55.5)$ & \multirow[t]{2}{*}{$<0.001$} \\
\hline & girl & $1029(45.2)$ & $4506(50.6)$ & $709(53.3)$ & $719(44.5)$ & \\
\hline \multirow[t]{2}{*}{ Region } & Urban & $1476(64.8)$ & 6233(69.9) & $1049(78.9)$ & $1337(82.8)$ & $<0.001$ \\
\hline & Rural & $803(35.2)$ & $2681(30.1)$ & $281(21.1)$ & $278(17.2)$ & \\
\hline Parental BMI, mean (sd) & & $25.5(4.8)$ & $26.4(4.81)$ & $26.9(5.05)$ & $27.53(5.2)$ & $<0.001^{\star}$ \\
\hline Paternal age at birth (years) & $<=30$ years & $1145(52.1)$ & $4470(51.9)$ & $676(52.1)$ & $799(50.9)$ & 0.31 \\
\hline \multirow[t]{2}{*}{$n(\%)$} & 31-35years & $524(23.9)$ & $2229(25.9)$ & $322(24.8)$ & $397(25.3)$ & \\
\hline & > 35years & $528(24)$ & 1907(22.2) & $300(23.1)$ & $373(23.8)$ & \\
\hline Maternal age at birth (years) & $<=30$ years & $1728(78.4)$ & $6777(78.8)$ & $1040(80.3)$ & $1221(78.2)$ & 0.78 \\
\hline \multirow[t]{2}{*}{$n(\%)$} & 31-35years & $344(15.6)$ & $1329(15.4)$ & 192(14.8) & $249(15.9)$ & \\
\hline & > 35years & $133(6)$ & $496(5.8)$ & $63(4.9)$ & $92(5.9)$ & \\
\hline Birth order & first & $923(41.2)$ & $3798(43.4)$ & $546(41.6)$ & $687(43)$ & $<0.001$ \\
\hline \multirow[t]{3}{*}{ n (\%) } & second & $576(25.7)$ & $2383(27.3)$ & $401(30.6)$ & $471(29.5)$ & \\
\hline & third & $374(16.7)$ & $1267(14.5)$ & 198(15.1) & $237(14.8)$ & \\
\hline & forth or more & $370(16.5)$ & $1295(14.8)$ & $167(12.7)$ & $203(12.7)$ & \\
\hline Number of children & $\leq 2$ & $863(38.0)$ & $3764(42.7)$ & $575(43.5)$ & 757(47.1) & $<0.001$ \\
\hline \multirow[t]{2}{*}{ n (\%) } & $3-4$ & $1005(44.3)$ & $3707(42)$ & $552(41.8)$ & $646(40.2)$ & \\
\hline & $\geq 5$ & $402(17.7)$ & $1348(15.3)$ & $194(14.7)$ & $203(12.6)$ & \\
\hline Physical activity & Low & $741(34.9)$ & $2746(33)$ & $441(35.1)$ & $494(32.7)$ & 0.03 \\
\hline \multirow[t]{2}{*}{ n (\%) } & Medium & $657(30.9)$ & 2767(33.2) & $440(35)$ & $521(34.5)$ & \\
\hline & High & $727(34.2)$ & 2810(33.8) & $377(30)$ & 495(32.8) & \\
\hline SES & Low & 797(36.6) & 2882(33.8) & $411(32.5)$ & $439(28.4)$ & $<0.001$ \\
\hline \multirow[t]{2}{*}{$\mathrm{n}(\%)$} & Medium & $706(32.4)$ & 2828(33.2) & $403(31.9)$ & $532(34.5)$ & \\
\hline & High & $675(31)$ & $2805(32.9)$ & $450(35.6)$ & $573(37.1)$ & \\
\hline Sleep duration, mean (sd) & & $8.58(1.23)$ & $8.57(1.23)$ & $8.59(1.26)$ & $8.54(1.25)$ & $0.74^{\star}$ \\
\hline Screen time & Low & 1904(85.5) & 7294(83.8) & 1076(82.9) & $1287(82.4)$ & 0.06 \\
\hline n (\%) & high & $324(14.5)$ & $1405(16.2)$ & $222(17.1)$ & $274(17.6)$ & \\
\hline Unhealthy food intake & low & 633(33.9) & $2286(32.6)$ & $320(31.2)$ & $450(35.2)$ & 0.25 \\
\hline \multirow[t]{2}{*}{$\mathrm{n}(\%)$} & moderate & $603(32.2)$ & $2289(34.1)$ & $346(33.7)$ & $428(33.5)$ & \\
\hline & high & 634(33.9) & 2339(33.3) & $360(35.1)$ & $400(31.3)$ & \\
\hline
\end{tabular}

* According to the ANOVA test, other $p$-values are based on chi-square test

SES $=$ Socioeconomic status, $\mathrm{SD}=$ Standard deviation 


\begin{tabular}{|c|c|c|c|c|c|c|}
\hline & & Underweight & Normal weight & Overweight & Obese & Pvalue \\
\hline Healthy food intake & low & $614(32.8)$ & 2334(33.3) & $339(33)$ & 438(34.3) & 0.75 \\
\hline \multirow[t]{2}{*}{$\mathrm{n}(\%)$} & moderate & $632(33.8)$ & 2382(34) & $358(34.9)$ & 405(31.7) & \\
\hline & high & $624(33.4)$ & $2298(32.8)$ & $329(32.1)$ & $435(34)$ & \\
\hline \multicolumn{7}{|c|}{ * According to the ANOVA test, other $p$-values are based on chi-square test } \\
\hline \multicolumn{7}{|c|}{ SES = Socioeconomic status, $\mathrm{SD}=$ Standard deviation } \\
\hline
\end{tabular}

Results of logistic regression analysis investigating the association between birth order and the number of children and child weight status are presented in Table 2. Odds of underweight was higher in the third children compared with the first children after adjusting for confounding factors including sex, age, region, birth weight, physical activity, screen time, SES, parental BMI, obesity, and diabetes history (OR: 1.22, 95\% Cl: 1.05-1.42). The second children were more likely to be overweight compared with the first children (OR: 1.17, 95\% Cl: 1.02-1.34); this association lost its significance after controlling for confounders. Children within threeto four-children families had higher odds of underweight in comparison to those within two-child families or less (OR: 1.14, 95\% Cl: 1.02-1.29), as well as children within five-child families or more compared to small families (OR: $1.25,95 \% \mathrm{Cl}: 1.05-1.48)$.

Moreover, students with $2-3$ siblings were less likely (OR: $0.87,95 \% \mathrm{Cl}: 0.77-0.97)$ to be obese than their single peers or peers with one sibling although its significance was attenuated after controlling for probable confounding factors.

Table 2. Results of the multinomial logistic regression of birth order and number of children and child weight status 


\begin{tabular}{|c|c|c|c|c|c|c|c|c|c|c|c|c|}
\hline & \multicolumn{3}{|c|}{ Underweight } & \multirow[b]{2}{*}{ Pvalue } & \multicolumn{4}{|c|}{ Overweight } & \multicolumn{4}{|c|}{ Obese } \\
\hline & $\begin{array}{l}\text { Crude } \\
\text { OR } \\
(95 \% \mathrm{CI})\end{array}$ & Pvalue & $\begin{array}{l}\text { Adjusted } \\
\text { OR* } \\
(95 \% \mathrm{CI})\end{array}$ & & $\begin{array}{l}\text { Crude } \\
\text { OR } \\
(95 \% \mathrm{CI})\end{array}$ & Pvalue & $\begin{array}{l}\text { Adjusted } \\
\text { OR* } \\
(95 \% \mathrm{CI})\end{array}$ & Pvalue & $\begin{array}{l}\text { Crude } \\
\text { OR } \\
(95 \% \mathrm{CI})\end{array}$ & Pvalue & $\begin{array}{l}\text { Adjusted } \\
\text { OR* } \\
(95 \% \mathrm{CI})\end{array}$ & Pvalue \\
\hline \multicolumn{13}{|c|}{ Birth order } \\
\hline First & 1 & & 1 & & 1 & & 1 & & 1 & & 1 & \\
\hline Second & $\begin{array}{l}0.99(0.88- \\
1.12)\end{array}$ & 0.93 & $\begin{array}{l}0.98(0.86- \\
1.11)\end{array}$ & 0.74 & $\begin{array}{l}1.17(1.02- \\
1.34)\end{array}$ & 0.03 & $\begin{array}{l}1.16(0.99- \\
1.35)\end{array}$ & 0.056 & $\begin{array}{l}1.09(0.96- \\
1.24)\end{array}$ & 0.18 & $\begin{array}{l}1.04(0.9- \\
1.19)\end{array}$ & 0.6 \\
\hline Third & $\begin{array}{l}1.21(1.06- \\
1.4)\end{array}$ & 0.005 & $\begin{array}{l}1.22(1.05- \\
1.42)\end{array}$ & 0.01 & $\begin{array}{l}1.09(0.91- \\
1.29)\end{array}$ & 0.35 & $\begin{array}{l}1.1(0.91- \\
1.35)\end{array}$ & 0.31 & $\begin{array}{l}1.03(0.88- \\
1.21)\end{array}$ & 0.69 & $\begin{array}{l}1.07(0.89- \\
1.3)\end{array}$ & 0.45 \\
\hline $\begin{array}{l}\text { Forth } \\
\text { or } \\
\text { more }\end{array}$ & $\begin{array}{l}1.18(1.03- \\
1.35)\end{array}$ & 0.02 & $\begin{array}{l}1.14(0.97- \\
1.34)\end{array}$ & 0.1 & $\begin{array}{l}0.9(0.74- \\
1.08)\end{array}$ & 0.25 & $\begin{array}{l}0.86(0.69- \\
1.07)\end{array}$ & 0.18 & $\begin{array}{l}0.87(0.73- \\
1.03)\end{array}$ & 0.09 & $\begin{array}{l}0.96(0.79- \\
1.17)\end{array}$ & 0.7 \\
\hline \multicolumn{13}{|c|}{ Number of children } \\
\hline$\leq 2$ & 1 & & 1 & & 1 & & 1 & & 1 & & 1 & \\
\hline $3-4$ & $\begin{array}{l}1.18(1.07- \\
1.31)\end{array}$ & 0.001 & $\begin{array}{l}1.14(1.02- \\
1.29)\end{array}$ & 0.03 & $\begin{array}{l}0.97(0.86- \\
1.1)\end{array}$ & 0.69 & $\begin{array}{l}0.98(0.85- \\
1.13)\end{array}$ & 0.78 & $\begin{array}{l}0.87(0.77- \\
0.97)\end{array}$ & 0.01 & $\begin{array}{l}0.88(0.77- \\
1.00)\end{array}$ & 0.05 \\
\hline$\geq 5$ & $\begin{array}{l}1.3(1.14- \\
1.49)\end{array}$ & $<0.001$ & $\begin{array}{l}1.25(1.05- \\
1.48)\end{array}$ & 0.01 & $\begin{array}{l}0.94(0.79- \\
1.12)\end{array}$ & 0.50 & $\begin{array}{l}0.99(0.8- \\
1.24)\end{array}$ & 0.96 & $\begin{array}{l}0.75(0.63- \\
0.88)\end{array}$ & 0.001 & $\begin{array}{l}0.85(0.69- \\
1.05)\end{array}$ & 0.14 \\
\hline
\end{tabular}

*Adjusted for sex, age, region, birth weight, physical activity, screen time, socio-economic status, parental BMI, obesity history, diabetes history.

\section{Discussion}

This study confirmed the association between the number of children, birth order, and later BMI in a nationally-representative sample of children and adolescents. The current findings showed that the odds of underweight was higher in the third children compared with the first children; this result remained significant even after adjusting for confounding factors. The second children were more likely to be overweight compared with the first children, but this association lost its significance after controlling for confounding factors. A previous study found that last-born children showed lower odds of obesity than only children (5). A study in Sweden showed that birth order was inversely associated with BMl; first-borns had a BMI of $0.8 \%$ and $1.1 \%$ higher than the second born and third born children, respectively (27). In contrast, some studies have reported that the oldest children were significantly associated with overweight or increased adiposity $(13,28)$. 
This association can be justified in light of the fact that lower-birth-order infants are more likely to be smaller at birth than laterborn infants $(15,29,30)$. The former group is tend to undergo catch-up growth, a pattern associated with obesity risk (14). Khong et al. (31) suggested that pregnancy leads to permanent anatomical changes in the spiral arteries that can be associated to the number of previous pregnancies. This finding suggests that birth weight can be increased with increasing parity. Some studies purpose that differences in fetal nutrition and changes in this in successive pregnancies, reflected in e.g. birth weight (the Developmental Origins Hypothesis), have been put forward $(12,14)$. Another study suggested that psychosocial origin may explain the associations. Interaction patterns between family members may be mentioned as the underlying mechanism explaining the association of birth order and weight status (32).

Also we found that children within three- to four-children families had higher OR of underweight in comparison to those within oneor two-child families, as well as children within five-child families or more compared to smaller families. Moreover, those children and adolescents with more than two siblings were less likely to be obese than their single peers or peers with one sibling; however, its significance was attenuated after controlling for potential confounding factors. A study found that children who had no siblings had the highest risk of obesity through 8 th grade (33). Another study reported that singletons were 1.30 times more likely to be overweight than their peers with at least one sibling (34). A longitudinal study conducted in the USA showed that only children had higher mean BMI compared to those who had at least two brothers, even after adjustment for possible confounding factors (8). In contrast, a study did not show any association between the number of siblings and overweight in Chinese adolescents (35).

The presence of siblings may provide greater opportunity for games and other physical activities (36). Hallal et al. (36) suggested that a higher number of siblings, regardless of the activity level of each individual sibling, promotes active lifestyles in the long run. Moreover, boys without any sibling have been shown to spend more time watching television than those with siblings (37). Siblings may also be a stimulus for child-to-child interactions, cooperative play, or activities that increase the time each child devotes to physical activity (38).

Previous studies have presented that the number of siblings may influence children's weight status through effects on parental time and attention allotted to children and on the nature and extent of interactions among siblings $(39,40)$. A previous study showed that single children had significantly higher intakes of many nutrients per $1000 \mathrm{kcal}$ compared to children with sibling(s) (41), which might be explained by the fact that a mother with one child is more concerned with persuading her child to eat and grow than is a mother with several children (42). Therefore, additional siblings may decrease parental attention and availability of food for each child, resulting in the reduction of the odds for overweight (43). Research has also suggested that children in singlechild families have considerably greater access to foods and thus intake more nutrients than children with siblings (41). One reason is that a mother with an only child tries to pursuade the child to eat compared a mother with more than one child (42). Accordingly, as the number of children increases there will be less food for each child, reducing the OR for overweight, especially in poor families (8).

This study was conducted on a large representative sample of Iranian children and adolescents; however, it has some limitations. Regarding the cross-sectional nature of the study, casual associations could not be provided. Moreover, we missed the pubertal status of the study participants, which might largely affect the body size interpretation. Furthermore, psychopathological variables and pathological eating behaviors were not considered in the present study.

\section{Conclusion}

The insights from this study can be used by practitioners and researchers to better identify children at risk. Since associations observed in this study are influenced by family practices and functioning, further exploration of underlying processes influencing family-based interventions is essential. The findings of this study can encourage practitioners and researchers to examine parenting practices used in single-child families for effective implementation of family-based program. Future studies can also survey parents about different interaction patterns among siblings and to the association of these patterns with obesity risk factors. The data on birth order and number of children data can be used as a novel and successful approach to identify at-risk children and to develop recommendations and interventions involving the home setting, aiming to help reduce pediatric obesity rates. 


\section{What Is Already Known On This Subject?}

The origin of obesity in children is complex and multiple factors including genetic, social, cultural and behavioral all seems to interact. Recent studies have suggested the most important variables associated with childhood obesity are family variables.

\section{What this study adds?}

In this study, birth order and number of family children were associated with underweight, overweight or obesity in a nationallyrepresentative sample of children and adolescents. Prevalence of obesity in first-born children was higher. Furthermore, our results showed that third-born children had higher odds of underweight than first-born children.

\section{Declarations}

\section{Ethics approval and consent to participate}

The study protocol was approved by the Research and Ethics Council of Isfahan University of Medical Sciences (code: 194049). Written informed consent and verbal assent were obtained from all the parents and students, respectively.

\section{Consent for publication}

Not applicable.

\section{Availability of data and material}

The datasets used and/or analyzed during the current study are available from the corresponding author on reasonable request.

\section{Competing interests}

The authors declare that they have no competing interests.

\section{Funding}

This study was conducted as part of a national surveillance program.

\section{Authors' contributions}

The concept of this study was proposed by Z.H., M.Q., This study was designed R.H., M.Q., R.K., Data collection or processing was done by R.H., M.E.M., Z.H., N.M., H.-S.E., S.S.D., M.G., Analysis or interpretation was performed by Z.H., M.Q., H.R, N.M., Literature search was done by H.-S.E., Z.H., This study was written by Z.H., H.-S.E., All authors have read and approved the manuscript.

\section{Acknowledgements}

The authors are thankful of the team working on this national project and all participants who cooperated with this study.

\section{References}

1. Kelishadi R, Haghdoost A-A, Sadeghirad B, Khajehkazemi R. Trend in the prevalence of obesity and overweight among Iranian children and adolescents: A systematic review and meta-analysis. Nutrition. 2014;30:393-400.

2. Finucane MM, Stevens GA, Cowan M, Danaei G, Lin JK, Paciorek CJ, et al. National, regional, and global trends in body-mass index since 1980: systematic analysis of health examination surveys and epidemiological studies with 960 country-years and 9.1 million participants. Lancet. 2011;377(9765):557-67.

3. Stevens GA, Singh GM, Lu Y, Danaei G, Lin JK, Finucane MM, et al. National, regional, and global trends in adult overweight and obesity prevalences. Popul Health Metr. 2012;10(1):22.

4. Gupta N, Shah P, Nayyar S, Misra A. Childhood obesity and the metabolic syndrome in developing countries. IndianJ Pediatr. 2013;80(1):28-37. 
5. Haugaard LK, Ajslev TA, Zimmermann E, ngquist LA, Sørensen TIA. Being an Only or Last-Born Child Increases Later Risk of Obesity. PLoS ONE. 2013;8(2):e56357.

6. Kopelman P, Jebb SA, Butland B. Executive summary: Foresight Tackling Obesities: Future Choices project. Obes Rev. 2007;1:vi-x.

7. Wang H, Sekine M, Chen X, Kanayama H, Yamagami T, Kagamimori S. Sib-size, birth order and risk of overweight in junior high school students in Japan: results of the Toyama Birth Cohort Study. Prev Med. 2007;44(1):45-51.

8. Chen AY, Escarce JJ. Family structure and childhood obesity, Early Childhood Longitudinal Study - Kindergarten Cohort. Prev Chronic Dis. 2010;7(3):A50.

9. Gopinath B, Baur LA, Burlutsky G, Robaei D, Mitchell P. Socio-economic, familial and perinatal factors associated with obesity in Sydney school children. J Paediatr Child Health. 2012;48:44-51.

10. Guedes DP, Rocha GD, Silva AJRM, Carvalhal IM, Coelho EM. Effects of social and environmental determinants on overweight and obesity among Brazilian schoolchildren from a developing region. Rev Panam Salud Publica. 2011;30:295-302.

11. Dahly DL, Adair LS. Does lower birth order amplify the association between high socioeconomic status and central adiposity in young adult Filipino males? Int J Obes (Lond). 2010;34(4):751-9.

12. Siervo M, Horta BL, Stephan BCM, Victora CG, Wells JCK. First-borns carry a higher metabolic risk in early adulthood: evidence from a prospective cohort study. PLoS One. 2010;5(11):e13907.

13. Celi F, Bini V, Giorgi GD, Molinari D, Faraoni F, Stefano GD, et al. Epidemiology of overweight and obesity among school children and adolescents in three provinces of central Italy, 1993-2001: study of potential influencing variables. Eur J Clin Nutr. 2003;57:1045-51.

14. Wells JCK, Hallal PC, Reichert FF, Dumith SC, Menezes AM, Victora CG. Associations of birth order with early growth and adolescent height, body composition, and blood pressure: prospective birth cohort from Brazil. Am J Epidemiol. 2011;174(9):1028-35.

15. Wilcox MA, Chang AM, Johnson IR. The effects of parity on birthweight using successive pregnancies. Acta Obstet Gynecol Scand. 1996;75:453-9.

16. Meller FdO, Assunção MCF, Schäfer AA, Mola CLd, Barros AJD, Dahly DL, et al. The influence of birth order and number of siblings on adolescent body composition: evidence from a Brazilian birth cohort study. Br J Nutr. 2015;114:118-25.

17. https://data.worldbank.org/indicator/SP.DYN.TFRT.IN/ [Internet]. World Bank. 2015 [cited Accessed November 28, 2017].

18. an Analysis of the Living Conditions of the Brazilian Population [Internet]. Brazilian Institute of Geography and Statistics. 2015.

19. Motlagh ME, Ziaodini H, Qorbani M, Taheri M, Aminaei T, Goodarzi A, et al. Methodology and early findings of the fifth survey of childhood and adolescence surveillance and prevention of adult noncommunicable disease: The caspian-v study. International Journal of Preventive Medicine. 2017;8.

20. Kelishadi R, Motlagh ME, Roomizadeh P, Abtahi SH, Qorbani M, Taslimi M. First report on path analysis for cardiometabolic components in a nationally representative sample of pediatric population in the Middle East and North Africa (MENA): the CASPIAN-III Study. Annals of Nutrition Metabolism. 2013;62:257-65.

21. Motlagh ME, Ziaodini H, Qorbani M, Taheri M, Aminaei T, Goodarzi A. Methodology and early findings of the fifth survey of childhood and adolescence surveillance and prevention of adult noncommunicable disease: The caspian-v study. International Journal of Preventive Medicine. 2017;8:4.

22. Health WO. Expert committee on physical status. Physical Status: The use and interpretation of anthropometry. Geneva: WHO: 1995.

23. Knowles K, Paiva L, Sanchez S, Revilla L, Lopez T, Yasuda M, et al. Waist circumference, body mass index, and other measures of adiposity in predicting cardiovascular disease risk factors among Peruvian adults. International journal of hypertension. 2011;2011.

24. Salmon J, Campbell KJ, Crawford DA. Television viewing habits associated with obesity risk factors: a survey of Melbourne schoolchildren. Med J Aust. 2006;184(2):64. 
25. Kelishadi R, Majdzadeh R, Motlagh M-E, Heshmat R, Aminaee T, Ardalan G, et al. Development and evaluation of a questionnaire for assessment of determinants of weight disorders among children and adolescents: The Caspian-IV study. International Journal of Preventive Medicine. 2012;3(10).

26. Pediatrics A. National High Blood Pressure Education Program Working Group on high blood pressure in children and adolescents. Pediatrics. 2004;114:iv-v.

27. Jelenkovic A, Silventoinen K, Tynelius P, Myrskylä M, Rasmussen F. Association of birth order with cardiovascular disease risk factors in young adulthood: a study of one million Swedish men. PLoS ONE. 2013;8(5):e63361.

28. Stettler N, Tershakovec AM, Zemel BS, Leonard MB, Boston RC, Katz SH, et al. Early risk factors for increased adiposity: a cohort study of African American subjects followed from birth to young adulthood. Am J Clin Nutr. 2000;72(2):378-83.

29. Karn MN, Penrose LS. Birth weight and gestation time in relation to maternal age, parity and infant survival. Ann Eugen. 1951;16:147-64.

30. Roberts DF, Tanner RE. Effects of parity on birth weight and other variables in a Tanganyika Bantu sample. Br J Prev Soc Med. 1963;17:209-15.

31. Khong TY, Adema ED, Erwich JJ. On an anatomical basis for the increase in birth weight in second and subsequent born children. Placenta. 2003;24:348-53.

32. Trent K, Spitze GD. Growing up without siblings and adult sociability behaviors. J Fam Issues. 2011;32(9):1178-204.

33. Chen AY, Escarce JJ. Family Structure and Childhood Obesity: An Analysis through 8th Grade. Matern Child Health J. 2014;18(7):1772-7.

34. Hunsberger M, Formisano A, Reisch LA, Bammann K, Moreno L, Henauw SD, et al. Overweight in singletons compared to children with siblings: the IDEFICS study. Nutr Diabetes. 2012;2(7):e35.

35. Hesketh T, Qu JD, Tomkin A. Health effects of family size: cross sectional survey in Chinese adolescents. Arch Dis Child. 2003;88(6):467-71.

36. Hallal PC, Wells JCK, Reichert FF, Anselmi L, Victora CG. Early determinants of physical activity in adolescence: prospective birth cohort study. BMJ. 2006;332:1002-7.

37. Bagley S, Salmon J, Crawford D. Family structure and children's television viewing and physical activity. Med Sci Sports Exerc. 2006;38:910-8.

38. Chen AY, Escarce JJ. Family structure and childhood obesity, early childhood longitudinal Study-Kindergarten Cohort. Prev Chronic Dis. 2010;7:A50.

39. Hesketh K, Crawford D, Salmon J, Jackson M, Campbell K. Associations between family circumstance and weight status of Australian children. Int J Pediatr Obes. 2007;2(2):86-96.

40. Schor EL. Family pediatrics: Report of the task force on the family. Pediatrics. 2003;111(6 Pt 2):1541-71.

41. Jacoby A, Altman DG, Cook J, Holland WW, Elliott A. Influence of some social and environmental factors on the nutrient intake and nutritional status of schoolchildren. Br J Prev Soc Med. 1975;29(2):116-20.

42. Whitelaw AG. The association of social class and sibling number with skinfold thickness in London schoolboys. Hum Biol. 1971;43(3):414-20.

43. Ochiai H, Shirasawa T, Ohtsu T, Nishimura R, Morimoto A, Obuchi R, et al. Number of siblings, birth order, and childhood overweight: a population-based cross-sectional study in Japan. BMC Public Health. 2012;12:766. 